\title{
Serum Levels of Stress Hormones and Oxidative Stress Biomarkers Differ according to Sasang Constitutional Type
}

\author{
Hyeong Geug Kim, ${ }^{1}$ Yoon Jung Kim, ${ }^{1}$ Yo Chan Ahn, ${ }^{2}$ and Chang Gue Son ${ }^{1}$ \\ ${ }^{1}$ Liver and Immunology Research Center, Daejeon Oriental Hospital of Daejeon University, 176-9 Daeheung-ro, Jung-gu, \\ Daejeon 302-724, Republic of Korea \\ ${ }^{2}$ Department of Health Service Management, Daejeon University, 62 Daehak-ro Yongun-dong, Song-gu, \\ Daejeon 300-716, Republic of Korea \\ Correspondence should be addressed to Chang Gue Son; ckson@dju.ac.kr
}

Received 18 January 2015; Revised 24 March 2015; Accepted 26 March 2015

Academic Editor: Salih Mollahaliloglu

Copyright (C) 2015 Hyeong Geug Kim et al. This is an open access article distributed under the Creative Commons Attribution License, which permits unrestricted use, distribution, and reproduction in any medium, provided the original work is properly cited.

\begin{abstract}
Objectives. This study investigated whether Sasang constitutional type is associated with differences in the serum levels of stress hormones and oxidative stress. Methods. A total of 236 participants (77 males and 159 females) were enrolled. The serum levels of cortisol, adrenaline, reactive oxygen species (ROS), and malondialdehyde (MDA) were analyzed. Results. The distribution of Sasang constitutional types was as follows: Taeumin, 35.6\%; Soumin, 33.0\%; and Soyangin, 31.4\%. The serum cortisol levels of Taeumin were significantly lower than Soumin ( $p<0.1$ in both sexes) and Soyangin ( $p<0.05$ in males and $p<0.1$ in females). The adrenaline levels were also significantly lower in Taeumin than in Soumin ( $p<0.05$ in males and $p<0.1$ in females) and Soyangin $(p<0.1$ in males). Serum ROS levels were significantly higher in Soyangin than in Taeumin and Soumin $(p<0.05$ in males), whereas MDA levels were significantly lower in Taeumin compared with Soumin and Soyangin $(p<0.05$ in males and $p<0.1$ in females). Conclusion. Taeumin type may tolerate psychological or oxidative stress better than other types, which suggests a biological mechanism to explain the different pathophysiological features of Sasang constitutional types.
\end{abstract}

\section{Introduction}

Sasang constitutional medicine (SCM) is a major branch of traditional Korean medicine that emphasizes the role of inherited psychological and physical traits in the development and treatment of diseases [1]. SCM was established and popularized by Lee (1837-1900), a Korean doctor, through his book Donguisusebowon [2], and it has since been widely adopted as a diagnostic and therapeutic tool in traditional Korean medicine [3].

SCM classifies people into four types according to their constitution: Taeyangin, Soyangin, Taeumin, and Soumin. In this context, "constitution" includes the body's structural and functional features, including psychological characteristics [4]. Current genetic science has shown that the genome critically affects the complex processes involved in health and disease [5], and the SCM classification is presumably related to macrolevel genomic differences among individuals [6].
Moreover, recent studies have found that certain Sasang types are significantly more susceptible to certain diseases; specifically, those with the Taeumin type are especially susceptible to metabolic syndrome, and those with the Soumin type are especially susceptible to irritable bowel syndrome (IBS) $[7,8]$.

Psychological or emotional stress, which is inevitable in modern life, is associated with both mental and physical health [9]. Moreover, psychological characteristics have been associated with Sasang constitutional types [10]. In addition, evidence has shown a strong connection between psychological stress and oxidative stress, prominent features of pathophysiological processes in a wide range of disorders or aging $[11,12]$. Therefore, we hypothesized that Sasang constitutional type would affect the serum levels of stress hormones, especially cortisol and adrenaline, and oxidative stress biomarkers including reactive oxygen species (ROS) and its lipid oxidation byproduct. 
To contribute to elucidating the biological explanation for SCM, we initially investigated whether the serum level of stress hormones and the degree of oxidative stress differ according to Sasang constitution.

\section{Methods}

2.1. Subjects. Self-reported healthy adults were recruited in South Korea, and those who had an established illness or were taking medication were excluded from the study. This study also excluded night workers, alcoholics, and subjects with self-reported severe psychological stress. Blood samples were collected at least 4 hours after participants' last meal before noon. Informed consent was obtained from each subject and the Ethics Committee of Daejeon University Hospital approved the study protocol (authorization number: DJOMC-119).

2.2. Classification of Sasang Constitution. The grouping of participants according to type of Sasang constitution was based on consideration of an integrative combination of facial, body shape, vocal, and questionnaire response features using Sasang constitutional analytic tool (SCAT). This automated Sasang constitution classification system developed by the Korea Institute of Oriental Medicine [13]. Every participant was classified as Taeumin, Soumin, Taeyangin, or Soyangin.

2.3. Determination of Serum Cortisol and Adrenaline Levels. Serum cortisol and adrenaline levels were determined using a cortisol ELISA kit (LDN GmbH \& Co., KG, Nordhorn, Germany) and an adrenalin ELISA kit (LDN GmbH \& Co, KG, Nordhorn, Germany), respectively, according to the manufacturer's protocol. Absorbance was measured using a spectrophotometer (Molecular Devices, Sunnyvale, CA).

2.4. Determination of Serum ROS Levels. The total quantity of ROS in the serum was determined according to Hayashi' method [14]. Briefly, N,N-diethyl-para-phenylenediamine (DEPPD) and ferrous sulfate solutions were prepared in advance. Five $\mu \mathrm{L}$ of standard solution or serum was added to $140 \mu \mathrm{L}$ of $0.1 \mathrm{M}$ sodium acetate buffer ( $\mathrm{pH} 4.8$ ) in 96-well plates and incubated at $37^{\circ} \mathrm{C}$ for $5 \mathrm{~min}$. A total of $100 \mu \mathrm{L}$ of DEPPD and ferrous mixture solution was added to each well, and the amount of ROS was determined at the saturation point at $505 \mathrm{~nm}$ using a spectrophotometer. Hydrogen peroxide was used to generate the calibration curve, and the standard and the results were expressed as equivalent to levels of hydrogen peroxide $\left(\mu \mathrm{mol} \mathrm{H}_{2} \mathrm{O}_{2}\right.$ equiv/L).

2.5. Determination of Serum Malondialdehyde (MDA) Levels. Serum lipid peroxide levels were determined using thiobarbituric acid (TBA) reactive substances (TBARS) as previously described [15]. Briefly, $250 \mu \mathrm{L}$ of serum or standard solution was added to $2.5 \mathrm{~mL}$ of $20 \%$ trichloroacetic acid (TCA). This was then mixed with $1 \mathrm{~mL}$ of $0.67 \%$ thiobarbituric acid (TBA) and heated at $10^{\circ} \mathrm{C}$ for $30 \mathrm{~min}$, followed by cooling on ice. After centrifugation at $3000 \times \mathrm{g}$ for $20 \mathrm{~min}$, the absorbance of the upper organic layer was measured at $535 \mathrm{~nm}$ with a spectrophotometer and compared with a 1,1,3,3-tetraethoxypropane (TEP) standard curve.

2.6. Statistical Analysis. Statistical analysis was performed using SAS statistical software (SAS Rel. 8.02; SAS Institute, Inc., Cary, NC, USA). Comparisons among Sasang constitution groups were performed by one-way ANOVA followed by paired Student's $t$-tests. $p$ values $<0.1$ were considered statistically significant. All data are expressed as means \pm standard deviations (SDs).

\section{Results}

3.1. Characteristics of Participants. A total of 236 adults, including 77 males (median age: $23 \mathrm{yr}$, range: 18-63) and 159 females (median age: $21 \mathrm{yr}$, range $18-77$ ), participated in this study. The proportions of Taeumin, Soumin, and Soyangin among total participants were $35.6 \%, 33.0 \%$, and $31.3 \%$ respectively. The sample included no participants with a Taeyangin constitution. Among males, 23.4\%, 45.5\%, and $31.2 \%$ were of Taeumin, Soumin, and Soyangin constitution, respectively; among females, $41.5 \%, 27.0 \%$, and $31.5 \%$ were of Taeumin, Soumin, and Soyangin constitution, respectively (Table 1).

The average heights of the three Sasang types were similar; however, the body weights of differed notably among categories. The average body mass index (BMI) differed significantly according to Sasang constitution among male, female, and total participants $(p<0.01)$. The BMI of those with a Taeumin constitution was significantly higher than that of participants with a Soumin $(p<0.01$ in male, female, and total subjects) or a Soyangin $(p<0.01$ in male, female, and total subjects) constitution, and the BMI of those with a Soumin constitution was significantly lower than that of participants with a Soyangin constitution $(p<0.05$ in male and total subjects, Table 1).

3.2. Serum Levels of Cortisol. The serum cortisol level of males was significantly higher than that of females $(20.0 \pm 8.9$ versus $16.3 \pm 7.5 \mathrm{ng} / \mathrm{mL}, p=0.002$ ). Males with a Taeumin constitution $(16.8 \pm 6.2 \mathrm{ng} / \mathrm{mL})$ had a significantly lower serum cortisol level than those with a Soumin (21.0 \pm $11.1 \mathrm{ng} / \mathrm{mL}, p=0.091)$ or a Soyangin $(20.9 \pm 6.5 \mathrm{ng} / \mathrm{mL}$, $p=0.049)$ constitution. This pattern was repeated in female: Taeumin $(14.9 \pm 5.5 \mathrm{ng} / \mathrm{mL})$ comparing to Soumin $(16.9 \pm$ $5.9 \mathrm{ng} / \mathrm{mL}, p=0.081)$ and Soyangin $(17.6 \pm 10.3 \mathrm{ng} / \mathrm{mL}, p=$ 0.096 ), respectively (Figure $1(\mathrm{a})$ ). No significant difference in serum cortisol was observed between Soumin and Soyangin constitutional groups $(p=0.685)$.

3.3. Serum Adrenaline Levels. The serum adrenaline level of males was slightly higher than that of females $(296.1 \pm 126.4$ versus $284.4 \pm 85.4 \mathrm{pg} / \mathrm{mL}, p=0.604)$. Males with a Taeumin constitution $(250.9 \pm 50.4 \mathrm{pg} / \mathrm{mL})$ had a significantly lower level of serum adrenaline than males with a Soumin $(321.3 \pm$ $165.3 \mathrm{ng} / \mathrm{mL}, p=0.027)$ or Soyangin $(291.0 \pm 230.9 \mathrm{pg} / \mathrm{mL}$, $p=0.069)$ constitution. A statistically significant difference 
TABLE 1: Characteristics of participants according to the Sasang classification.

\begin{tabular}{|c|c|c|c|c|}
\hline $\begin{array}{l}\text { Sex } \\
\text { (number) }\end{array}$ & Characteristics & Taeumin & Soumin & Soyangin \\
\hline \multirow{5}{*}{$\begin{array}{l}\text { Male } \\
(77)\end{array}$} & Number (\%) & $18(23.4 \%)$ & $35(45.4 \%)$ & $24(31.2 \%)$ \\
\hline & Median age (yr, range) & $23(18-64)$ & $21(17-77)$ & $21(17-77)$ \\
\hline & Average height (cm) & $172.9 \pm 5.2$ & $172.6 \pm 6.6$ & $174.6 \pm 5.9$ \\
\hline & Average weight (kg) & $81.7 \pm 8.2$ & $67.3 \pm 7.7$ & $73.3 \pm 7.3$ \\
\hline & Mean BMI & $27.3 \pm 2.2$ & $22.5 \pm 1.7$ & $24.3 \pm 2.5$ \\
\hline \multirow{5}{*}{$\begin{array}{l}\text { Female } \\
(159)\end{array}$} & Number (\%) & $66(41.5 \%)$ & $43(27.0 \%)$ & $50(31.5 \%)$ \\
\hline & Median age (yr, range) & $23(18-64)$ & $21(17-77)$ & $21(17-77)$ \\
\hline & Average height (cm) & $162.6 \pm 5.8$ & $160.5 \pm 4.8$ & $159.8 \pm 4.8$ \\
\hline & Average weight (kg) & $63.1 \pm 12.1$ & $51.1 \pm 7.4$ & $54.8 \pm 5.4$ \\
\hline & Average BMI & $24.0 \pm 4.3$ & $18.8 \pm 2.6$ & $21.4 \pm 1.7$ \\
\hline \multirow{5}{*}{$\begin{array}{l}\text { Total } \\
(236)\end{array}$} & Number $(\%)$ & $84(35.6 \%)$ & $78(33.0 \%)$ & $74(31.4 \%)$ \\
\hline & Median age (yr, range) & $23(18-64)$ & $21(17-77)$ & $21(17-77)$ \\
\hline & Average height $(\mathrm{cm})$ & $164.4 \pm 6.2$ & $166.0 \pm 8.3$ & $164.6 \pm 8.7$ \\
\hline & Average weight (kg) & $67.1 \pm 13.7$ & $58.4 \pm 11.1$ & $60.9 \pm 10.8$ \\
\hline & Mean BMI & $24.7 \pm 4.2$ & $21.0 \pm 2.6$ & $22.3 \pm 2.4$ \\
\hline
\end{tabular}

${ }^{* * *}$ Comparisons of the BMIs of those with different Sasang constitutions $(p<0.01)$ were performed with ANOVAs. Those with a Taeumin constitution had significantly higher BMIs than those with a Soumin $(p<0.01$ in male, female, and total subjects) or Soyangin $(p<0.01$ in male, female, and total subjects) constitution, and those with a Soumin constitution had significantly lower BMIs than those with Soyangin constitution ( $p<0.05$ in male and total subjects). BMI: body mass index.

was observed between Taeumin $(246.9 \pm 55.4 \mathrm{pg} / \mathrm{mL})$ and Soumin $(333.2 \pm 118.0 \mathrm{ng} / \mathrm{mL}, p=0.084)$, but Soyangin $(290.3 \pm 54.4 \mathrm{ng} / \mathrm{mL}, p=0.198)$, for serum adrenaline in females (Figure $1(\mathrm{~b})$ ).

3.4. Serum ROS Levels. Males and females had almost identical serum ROS levels overall (178.6 \pm 81.4 versus $189.3 \pm$ $89.8 \mu \mathrm{M}, p=0.382)$. Soyangin males $(233.3 \pm 93.5 \mu \mathrm{M})$ had a significantly higher level than Taeumin $(171.5 \pm 73.9 \mu \mathrm{M}, p<$ $0.05)$ and Soumin $(168.9 \pm 86.5 \mu \mathrm{M}, p<0.05)$ males, but no significant differences were observed in females (Taeumin $181.0 \pm 93.8$ versus Soumin $177.2 \pm 69.8$ versus Soyangin $176.5 \pm 75.0 \mu \mathrm{M}$, resp., Figure $1(\mathrm{c}))$.

3.5. Serum MDA Levels. The overall serum MDA levels of males and females were very similar $(6.4 \pm 5.6$ versus $6.0 \pm$ $6.8 \mu \mathrm{M}, p=0.415)$. Taeumin males $(4.1 \pm 4.8 \mu \mathrm{M})$ had a significantly lower value compared with Soumin $(6.7 \pm 6.6 \mu \mathrm{M}$, $p=0.039)$ and Soyangin $(7.6 \pm 6.2 \mu \mathrm{M}, p=0.040)$ males, and this pattern was repeated in females (Taeumin: $3.2 \pm$ $4.0 \mu \mathrm{M}$; Soumin: $5.4 \pm 5.5 \mu \mathrm{M}, p=0.081$; Soyangin: $6.8 \pm$ $3.8 \mu \mathrm{M}, p=0.062$, Figure $1(\mathrm{~d}))$. No significant difference was observed between Soumin and Soyangin constitutions in males $(p=0.594)$ or females $(p=0.732)$.

\section{Discussion}

Inherited genomic variance is a critical contributor to individual differences in the development of various diseases [16]. SCM stresses the importance of inborn physical and psychological characteristics, which might be linked to macrogenomic features $[17,18]$. Several studies have found that the high incidence of certain disorders and different drug responses are associated with Sasang constitutiondependent genomic features, likely the significantly different distributions of Prol2Ala polymorphism or haplotypes of multidrug resistance 1 (MDR1) gene $[19,20]$.

We examined whether the serum levels of two representative stress hormones and oxidative stress markers differ according to Sasang constitution. Psychological stress and oxidative stress have been established as general contributors to various disorders, including cancer and immunological and age-related diseases $[21,22]$. The total proportions of Taeumin, Soumin, and Soyangin constitutional types in this sample were $35.6 \%, 33.0 \%$, and $31.3 \%$, respectively (Table 1). No participant was classified as Taeyangin, probably because this type is extremely rare in the Korean population [23].

Taeumin males and females showed relatively lower concentrations of serum cortisol and adrenaline compared with Soumin and Soyangin males and females (Figures 1(a) and $1(\mathrm{~b})$ ). Cortisol and adrenaline are considered typical stress hormones that are released via activation of the hypothalamic-pituitary-adrenal (HPA) axis under stress [9]. These stress hormones have a harmful effect on multiple target organs and systems, with outcomes including chronic pain, immunosuppression, and psychological disorders [24, 25]. Our results suggest a partial explanation of clinical data showing that Soumins are vulnerable to stress and irritable bowel syndrome (IBS) [8]. Individuals with IBS were known to have the sustained HPA axis activity [26], and then Soumins showed the highest levels of both cortisol and adrenaline in our study. Additionally, activation of the HPA axis is associated with acceleration in oxidative stress via unbalanced redox, including excessive production of mitochondrial ROS $[27,28]$. In our study, the serum levels of ROS 


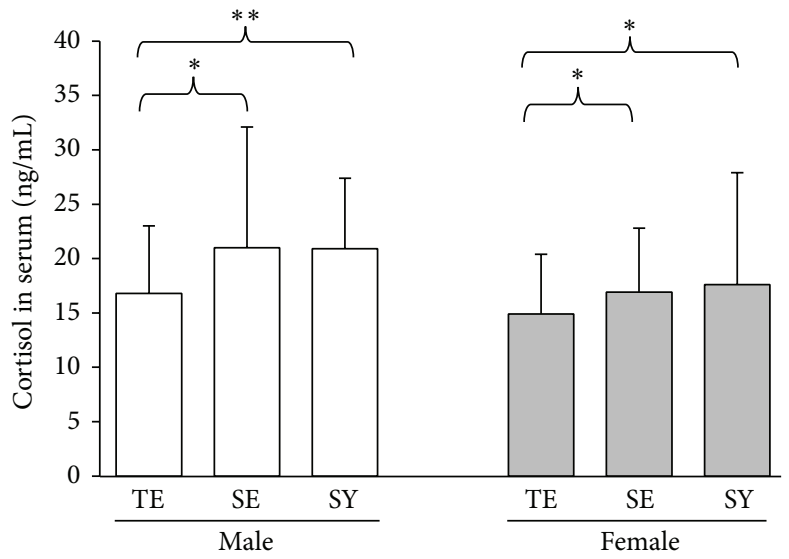

(a)

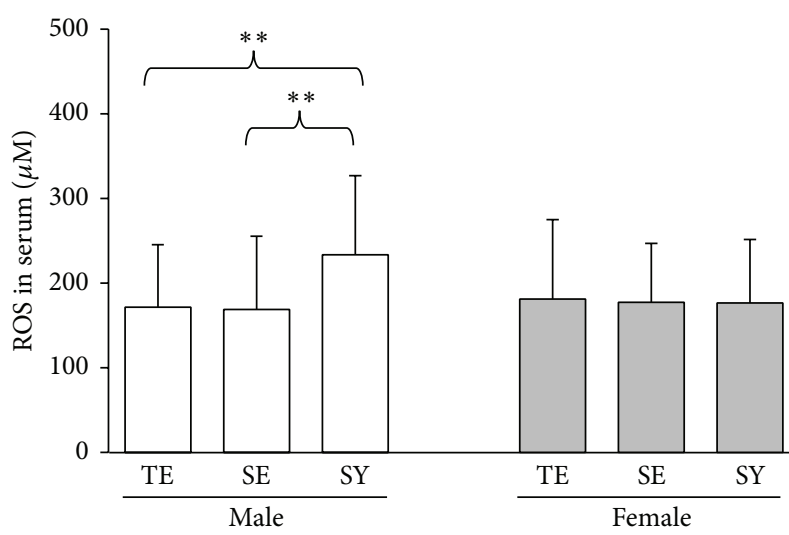

(c)

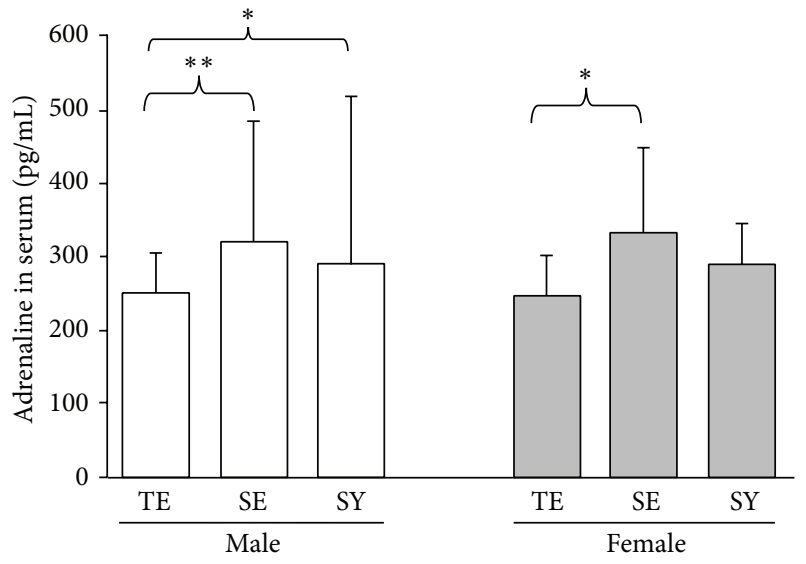

(b)

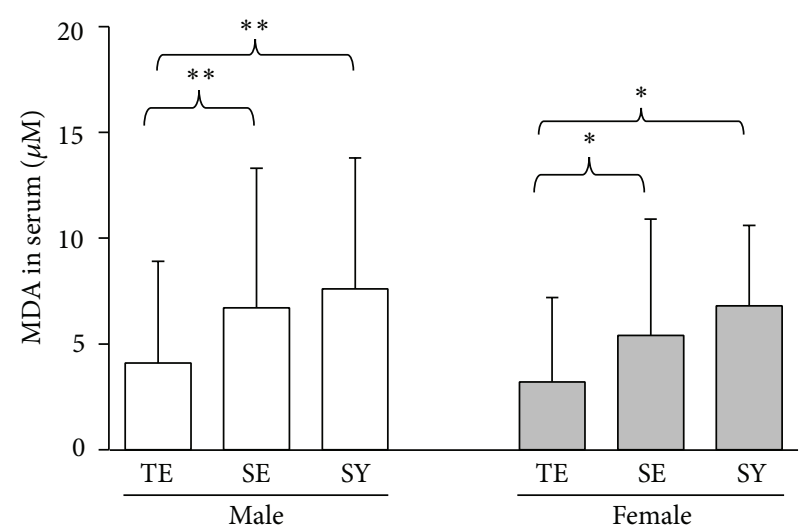

(d)

Figure 1: Serum levels of stress-related hormones and oxidative stress biomarkers. Blood was collected from healthy adults. The serum levels of cortisol (a) and adrenalin (b), reactive oxidative species (ROS (c)), and malondialdehyde (MDA (d)) were measured. Results are expressed as means \pm SDs. Statistical significance was set at ${ }^{*} p<0.1$ and ${ }^{* *} p<0.05$.

and its lipid peroxidation product MDA were low-high in Taeumins but high in Soumins and Soyangins (Figures 1(c) and $1(\mathrm{~d})$ ). Oxidative stress is implicated in diverse pathophysiological conditions, including inflammation, neurodegenerative diseases, and cancer [29]. Our previous study found that the incidence of cancer was significantly lower in Taeumins than in Soumins or Soyangins [30]. The serum cortisol levels however would be affected by time point of blood sample because circadian rhythm in the release of cortisol and adrenaline is well known [31, 32].

The analysis of physical features showed that BMIs differed significantly according to Sasang constitutional type; those with the Taeumin type had the highest BMIs, followed by those with the Soyangin type and those with the Soumin type (Table 1), which is consistent with results from other researches [33]. BMI is well known as a risk factor for type 2 diabetes; however, one study found that Taeumin constitution is an independent risk factor for this disease regardless of BMI score [34]. In our study, BMI values did not reflect a pathogenic level; the maximum value was $27.3 \pm 2.2$ (in Taeumins), and the minimal value was $22.5 \pm 1.7$ (in
Soumins). Moreover, a huge cohort study with 120,700 East Asians found that, unlike Westerners, Koreans with a BMI between 22.6 and 27.5 showed the lowest risk of death [35]. Obesity is generally positively associated with oxidative stress [36]; however, our results did not show the correlation between BMI values and levels of ROS or MDA.

Our study has some limitations such as relatively small number and young age of participants. We also adopted $p=$ 0.1 as the cutoff for statistical significance. Clinical studies may accept $p<0.1$ as the threshold for statistical significance if doing so makes scientific sense but does not cause harm, as may be the case in drug tests [37]. The choice of $p=0.1$, however, could increase the possibility of type 1 error; therefore we need to interpret our data with care.

In conclusion, our results carefully propose the differences in the serum levels of stress hormones and the oxidative stress markers across Sasang constitutional types, especially in Taeumins compared with Soumins and Soyangins. This finding would contribute to SCM-based practices by informing future research regarding the mechanisms underpinning such differences. 


\section{Conflict of Interests}

The authors declare that there is no conflict of interests regarding the publication of this paper.

\section{Acknowledgment}

This work was supported by a National Research Foundation of Korea (NRF) grant funded by the Ministry of Science, ICT \& Future Planning (no. 2006-2005173).

\section{References}

[1] H. Chae, I. K. Lyoo, S. J. Lee et al., "An alternative way to individualized medicine: psychological and physical traits of Sasang typology," Journal of Alternative and Complementary Medicine, vol. 9, no. 4, pp. 519-528, 2003.

[2] J. M. Lee, "Longevity and life preservation in eastern medicine," in Longevity and Life Preservation in Oriental Medicine, S. H. Choi, Ed., Kyung Hee University Press, Seoul, Republic of South Korea, 1996.

[3] J. Lee, Y. Jung, J. Yoo, E. Lee, and B. Koh, "Perspective of the human body in sasang constitutional medicine," EvidenceBased Complementary and Alternative Medicine, vol. 6, supplement 1, pp. 31-41, 2009.

[4] J.-H. Yoo, J.-W. Kim, K.-K. Kim, J.-Y. Kim, B.-H. Koh, and E.J. Lee, "Sasangin diagnosis questionnaire: test of reliability," The Journal of Alternative and Complementary Medicine, vol. 13, no. 1, pp. 111-122, 2007.

[5] C. Gonzaga-Jauregui, J. R. Lupski, and R. A. Gibbs, "Human genome sequencing in health and disease," Annual Review of Medicine, vol. 63, pp. 35-61, 2012.

[6] B.-Y. Kim, H.-J. Jin, and J. Y. Kim, "Genome-wide association analysis of sasang constitution in the Korean population," Journal of Alternative and Complementary Medicine, vol. 18, no. 3, pp. 262-269, 2012.

[7] E. Jang, Y. Baek, K. Park, and S. Lee, "The sasang constitution as an independent risk factor for metabolic syndrome: propensity matching analysis," Evidence-Based Complementary and Alternative Medicine, vol. 2013, Article ID 492941, 6 pages, 2013.

[8] S. K. Lee, D. W. Yoon, H. Yi et al., "So-eum type as an independent risk factor for irritable bowel syndrome: a populationbased study in Korea," The Journal of Alternative and Complementary Medicine, vol. 20, no. 11, pp. 846-852, 2014.

[9] J. M. Koolhaas, A. Bartolomucci, B. Buwalda et al., "Stress revisited: a critical evaluation of the stress concept," Neuroscience \& Biobehavioral Reviews, vol. 35, no. 5, pp. 1291-1301, 2011.

[10] S. J. Lee, S. H. Park, C. R. Cloninger, Y. H. Kim, M. Hwang, and H. Chae, "Biopsychological traits of Sasang typology based on Sasang personality questionnaire and body mass index," $B M C$ Complementary and Alternative Medicine, vol. 14, article 315, 2014.

[11] M. Colaianna, S. Schiavone, M. Zotti et al., "Neuroendocrine profile in a rat model of psychosocial stress: relation to oxidative stress," Antioxidants \& Redox Signaling, vol. 18, no. 12, pp. 13851399, 2013.

[12] R. S. Sohal and W. C. Orr, "The redox stress hypothesis of aging," Free Radical Biology and Medicine, vol. 52, no. 3, pp. 539-555, 2012.

[13] J.-H. Do, E. Jang, B. Ku, J.-S. Jang, H. Kim, and J. Y. Kim, "Development of an integrated Sasang constitution diagnosis method using face, body shape, voice, and questionnaire information," BMC Complementary and Alternative Medicine, vol. 12, article 85, 2012.

[14] I. Hayashi, Y. Morishita, K. Imai, M. Nakamura, K. Nakachi, and T. Hayashi, "High-throughput spectrophotometric assay of reactive oxygen species in serum," Mutation Research, vol. 631, no. 1, pp. 55-61, 2007.

[15] A.-A. M. Kamal, A. Gomaa, M. El Khafif, and A. S. Hammad, "Plasma lipid peroxides among workers exposed to silica or asbestos dusts," Environmental Research, vol. 49, no. 2, pp. 173180, 1989.

[16] S. Gabriel, "Variation in the human genome and the inherited basis of common disease," Seminars in Oncology, vol. 33, supplement 11, pp. 46-49, 2006.

[17] B.-Y. Kim, S.-G. Yu, J.-Y. Kim, and K. H. Song, "Pathways involved in sasang constitution from genome-wide analysis in a korean population," Journal of Alternative and Complementary Medicine, vol. 18, no. 11, pp. 1070-1080, 2012.

[18] C. S. Yin, H. J. Park, J.-H. Chung, H.-J. Lee, and B.-C. Lee, "Genome-wide association study of the four-constitution medicine," Journal of Alternative and Complementary Medicine, vol. 15, no. 12, pp. 1327-1333, 2009.

[19] B.-C. Lee, H.-K. Doo, S.-Y. Ahn et al., "Peroxisome proliferatoractivated receptor- $\gamma$ Prol2Ala polymorphism is associated with the susceptibility to ischemic stroke in Taeeumin classified by Sasang medicine," Neurological Research, vol. 29, no. 1, pp. S32S37, 2007

[20] H.-J. Kim, S. Y. Hwang, J.-H. Kim et al., "Association between genetic polymorphism of multidrug resistance 1 gene and sasang constitutions," Evidence-Based Complementary and Alternative Medicine, vol. 6, supplement 1, pp. 73-80, 2009.

[21] S. Reuter, S. C. Gupta, M. M. Chaturvedi, and B. B. Aggarwal, "Oxidative stress, inflammation, and cancer: how are they linked?” Free Radical Biology and Medicine, vol. 49, no. 11, pp. 1603-1616, 2010.

[22] J.-P. Gouin, L. Hantsoo, and J. K. Kiecolt-Glaser, "Immune dysregulation and chronic stress among older adults: a review," NeuroImmunoModulation, vol. 15, no. 4-6, pp. 251-259, 2008.

[23] T. G. Lee, M. W. Hwang, T. I. Ham, B. K. Choi, B. H. Koh, and I. B. Song, "A study on distributional rate of Sasangin in Korea," Journal of Sasang Constitution Medicine, vol. 17, no. 3, pp. 12-21, 2005.

[24] S. M. Staufenbiel, B. W. J. H. Penninx, A. T. Spijker, B. M. Elzinga, and E. F. C. van Rossum, "Hair cortisol, stress exposure, and mental health in humans: a systematic review," Psychoneuroendocrinology, vol. 38, no. 8, pp. 1220-1235, 2013.

[25] F. Marino and M. Cosentino, "Adrenergic modulation of immune cells: an update," Amino Acids, vol. 45, no. 1, pp. 5571, 2013.

[26] P. J. Kennedy, J. F. Cryan, E. M. Quigley, T. G. Dinan, and G. Clarke, "A sustained hypothalamic-pituitary-adrenal axis response to acute psychosocial stress in irritable bowel syndrome," Psychological Medicine, vol. 44, no. 14, pp. 3123-3134, 2014.

[27] K. Aschbacher, A. O’Donovan, O. M. Wolkowitz, F. S. Dhabhar, Y. Su, and E. Epel, "Good stress, bad stress and oxidative stress: insights from anticipatory cortisol reactivity," Psychoneuroendocrinology, vol. 38, no. 9, pp. 1698-1708, 2013.

[28] P. Hašková, L. Koubková, A. Vávrová et al., “Comparison of various iron chelators used in clinical practice as protecting agents against catecholamine-induced oxidative injury and cardiotoxicity," Toxicology, vol. 289, no. 2-3, pp. 122-131, 2011. 
[29] R. Thanan, S. Oikawa, Y. Hiraku et al., "Oxidative stress and its significant roles in neurodegenerative diseases and cancer," International Journal of Molecular Sciences, vol. 16, no. 1, pp. 193217, 2015.

[30] J. H. Lee, W. Kang, J. H. Cho, C. K. Cho, H. S. Yoo, and C. G. Son, "Cancer incidence varies significantly depending on Sasang constitution of Traditional Korean Medicine," Journal of Traditional Chinese Medicine, vol. 33, no. 3, pp. 312-315, 2013.

[31] Y. Chida and A. Steptoe, "Cortisol awakening response and psychosocial factors: a systematic review and meta-analysis," Biological Psychology, vol. 80, no. 3, pp. 265-278, 2009.

[32] T. Akerstedt and L. Levi, "Circadian rhythms in the secretion of cortisol, adrenaline and noradrenaline," European Journal of Clinical Investigation, vol. 8, no. 2, pp. 57-58, 1978.

[33] D. D. Pham, J.-H. Do, B. Ku, H. J. Lee, H. Kim, and J. Y. Kim, "Body mass index and facial cues in Sasang typology for young and elderly persons," Evidence-Based Complementary and Alternative Medicine, vol. 2011, Article ID 749209, 9 pages, 2011.

[34] N. H. Cho, J. Y. Kim, S. S. Kim, S. K. Lee, and C. Shin, "Predicting type 2 diabetes using Sasang constitutional medicine," Journal of Diabetes Investigation, vol. 5, no. 5, pp. 525-532, 2014.

[35] W. Zheng, D. F. McLerran, B. Rolland et al., "Association between body-mass index and risk of death in more than 1 million Asians," The New England Journal of Medicine, vol. 364, no. 8, pp. 719-729, 2011.

[36] L. Marseglia, S. Manti, G. D'Angelo et al., "Oxidative stress in obesity: a critical component in human diseases," International Journal of Molecular Sciences, vol. 16, no. 1, pp. 378-400, 2014.

[37] T. Dahiru, "P-value, a true test of statistical significance? A cautionary note," Annals of Ibadan Postgraduate Medicine, vol. 6, no. 1, pp. 21-26, 2011. 


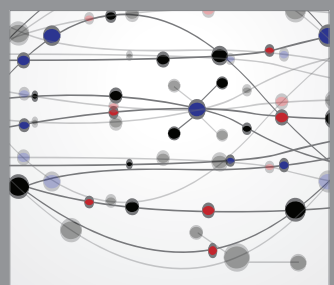

The Scientific World Journal
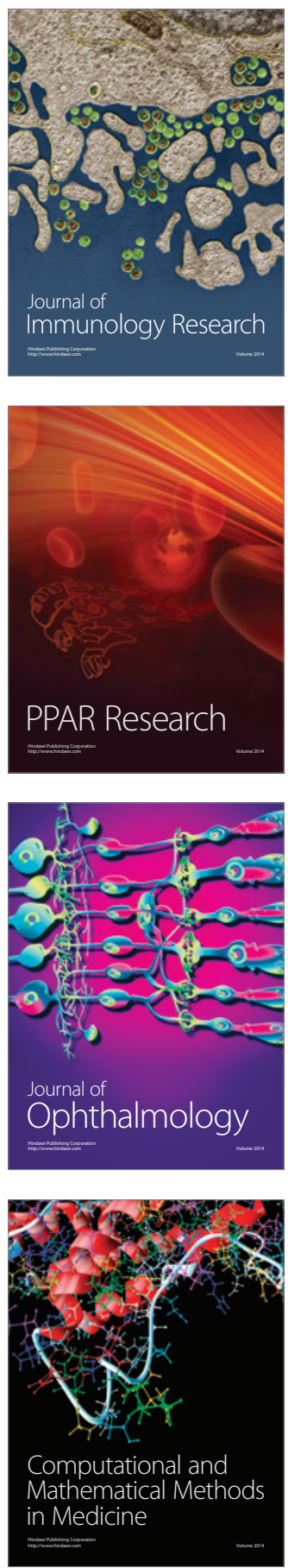

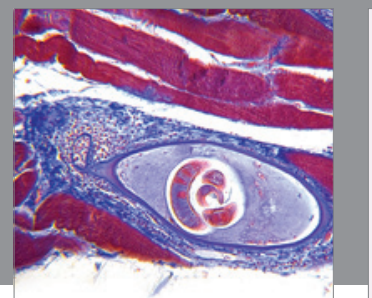

Gastroenterology

Research and Practice
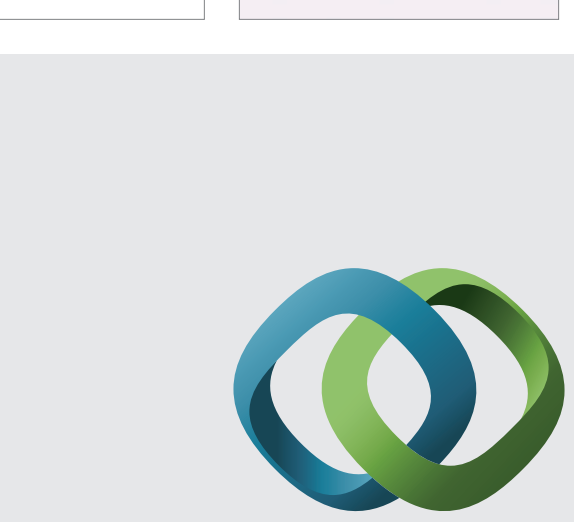

\section{Hindawi}

Submit your manuscripts at

http://www.hindawi.com
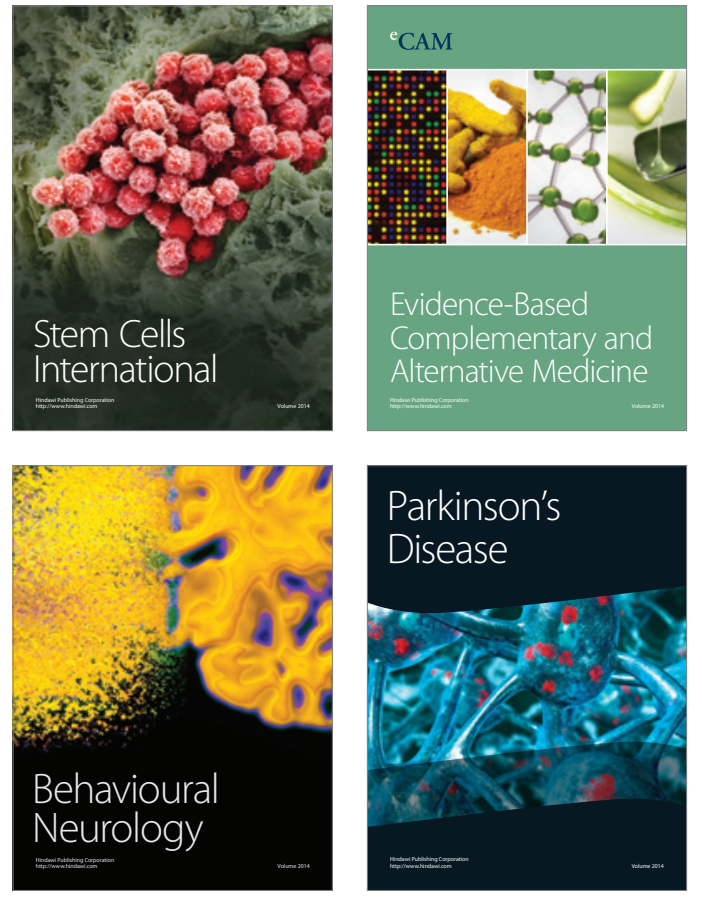
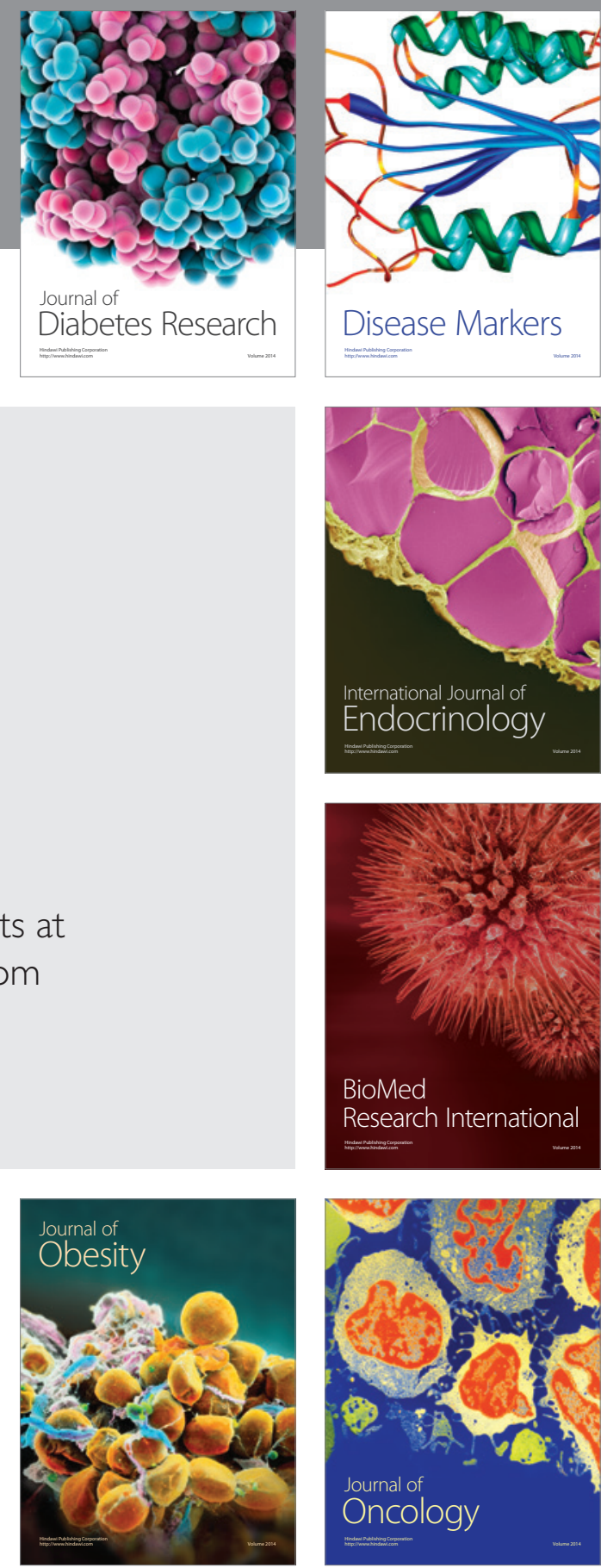

Disease Markers
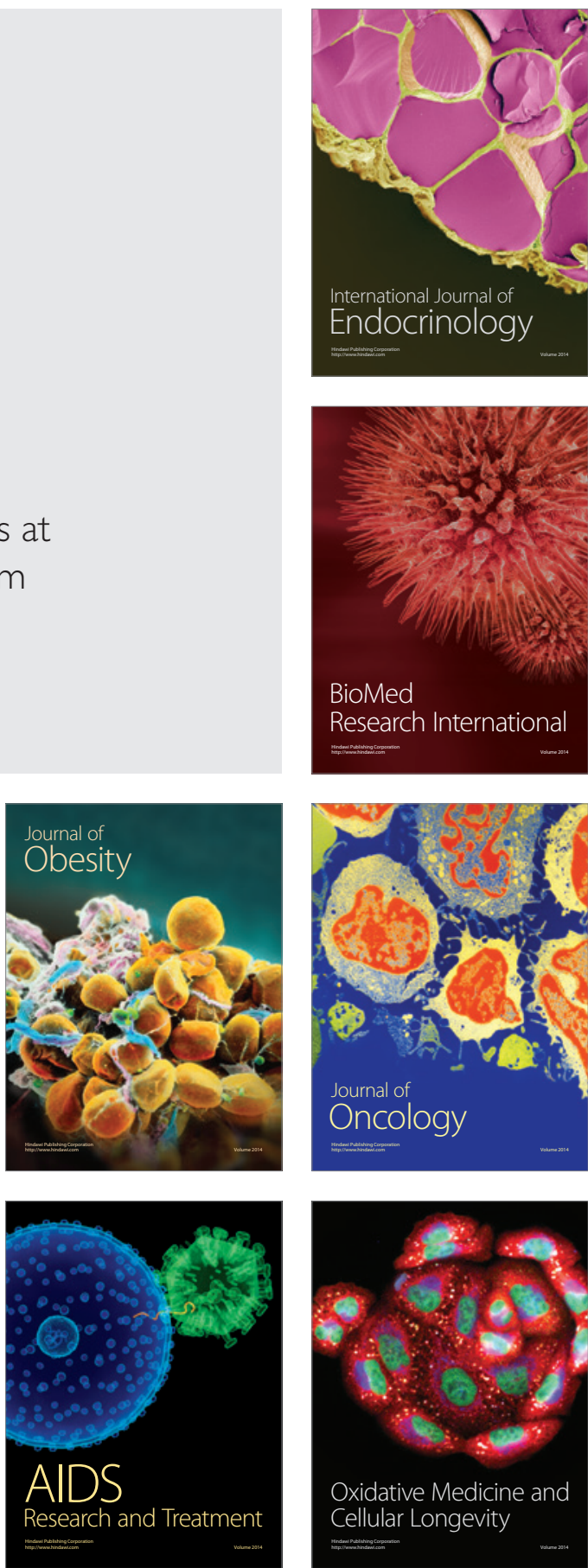